\title{
SHORE OR MARINA PROTECTION USING A CLOSED FRAME FI ON PILES
}

haikal e.m

\begin{abstract}
Shore or marina protection using a closed frame fixed on two rows of piles was examined experimentally for low and moderate waves. Different parameters affecting the wave diffraction around the proposed structure were taken into considerations such as, the relative draft and width of the floating structure, pile diameter, pile spacing, wave characteristics and sea bed slope. The efficiency of the proposed breakwater model to control the wave energy was measured at different locations around the structure. It is concluded that; good efficiency of the proposed model is obtained when the relative draft is for short and intermediate waves especially on a sloping beach
\end{abstract}

